\title{
ON THE FACTORIZATION OF INEQUALITIES
}

\author{
L. LEINDLER
}

Abstract. We generalize two theorems pertaining to the factorization of inequalities of infinite numerical series.

Mathematics subject classification (1991): 26D15, 40A05, 40A99.

Key words and phrases: Inequalities for sums, factorization, power-monotone sequences.

\section{REFERENCES}

[1] G. BennetT, Factorizing the Classical Inequalities, Memoirs of Amer. Math. Soc. 120 (1996, Number 576), 1-130.

[2] L. LEINDLER, Two Hardy-Bennett-type theorems, Acta Math. Hung. (to appear).

[3] _ An addition to factorization of inequalites, Math. Pannonica 10 (1999), 61-65.

[4] - An attachment to factorization of inequalities, Acta Sci. Math. (Szeged), 65 (1999), 85-92. 